\title{
Anti-Proliferative Activity and Tubulin Targeting of Novel Micro and Nanoparticles Complexes of 4-Amino-3-Thion-I,2,4-Triazole Derivatives
}

\author{
Atheer Ali $^{1}$, Rehab Al-Hassani ${ }^{1}$, Dhia Hussain ${ }^{1}$, Majid Jabir ${ }^{2}$, Hamid Meteab ${ }^{3}$ \\ ${ }^{1}$ Department of Chemistry, College of Science, Al-Mustansyah University, Baghdad, Iraq. \\ ${ }^{2}$ Division of Biotechnology, Department of Applied Science, University of Technology, Baghdad, Iraq. \\ ${ }^{3}$ Ministry of Higher Education and Scientific Research, Iraq. \\ Corresponding author. E-mail: msj_iraq@yahoo.com
}

Received: Oct. 28, 2019; Accepted: Feb. 26, 2020; Published: Feb. 26, 2020.

Citation: Atheer Ali, Rehab Al-Hassani, Dhia Hussain, Majid Jabir, and Hamid Meteab, Anti-Proliferative Activity and Tubulin Targeting of Novel Micro and Nanoparticles Complexes of 4-Amino-3-Thion-1,2,4-Triazole Derivatives. Nano Biomed. Eng., 2020, 12(I): 75-89. DOI: 10.5101/nbe.v12i1.p75-89.

\begin{abstract}
In this study, novel micro and nanoparticle complexes of $\mathrm{Ag}(\mathrm{I}), \mathrm{Ni}(\mathrm{II})$, and $\mathrm{Pd}(\mathrm{II})$ ion with new asymmetrical Schiff base triazole ligand (4-(((3-mercapto-5-(naphthalen-1-ylmethyl)-4H-1,2,4-triazol-4-yl) imino)methyl)phenol) were prepared. The Schiff base micro complexes were identified using Fouriertransform infrared spectroscopy (FTIR), Ultraviolet-visible spectroscopy (UV-Vis), flame atomic absorption, elemental analysis C.H.N.S, conductivity measurements and magnetic susceptibility. New nanoparticles Schiff base triazole ligand (4-(((3-mercapto-5-(naphthalen-1-ylmethyl)-4H-1,2,4triazol-4-yl)imino)methyl)phenol) ligand and $\mathrm{Ag}(\mathrm{I}), \mathrm{Ni}(\mathrm{II})$ and $\mathrm{Pd}(\mathrm{II})$ complexes were synthesized as a novel compounds by using sonication method, and were fully characterized by using FTIR, atomic force microscopy (AFM), scanning electron microscope (SEM), and X-ray powder diffraction (XRD). The antioxidant activity of tested compounds was tested using DPPH assay. The effect of synthetic novel compounds on cancer cell line MCF-7 proliferation was measured by MTT assay. The ability of synthetic novel compounds in induction of apotosis was achieved using acridine orange/ethidium bromide $(\mathrm{AO} / \mathrm{EB})$ stains. We found that the synthetic novel compounds had the potential to inhibit growth of cancer cell at low concentrations. The effect of synthetic compounds on cell growth and proliferation of MCF-7 cells was associated with cell cycle arrest, and increased apoptosis. Our results showed that the synthetic novel compounds inhibited cancer cell line proliferation with a mechanism of action similar to that of other tubulin inhibitors. In conclusion, the results of this study indicate that synthetic novel compounds represent a new chemo type with a novel mechanisms of action and that it has the potential to be developed for tumor therapy.
\end{abstract}

Keywords: Schiff base triazole; Nanoparticle complexes; DPPH; Anti-proliferative; Tubulin targeting

\section{Introduction}

Since the discovery of heterocyclic nucleus of 1,2,4-triazoles in chemistry, their integrate heterocyclic derivatives symbolized very interesting group of compounds having a varied spectrum of biological activities. 1,2,4-triazoles exhibit antiinflammatory activity, antibacterial, antimycobacterial, anticonvulsant, antifungal and antidepressant [1] effects, as well as can be anticancer, antimalarial, analgesic, and central nervous system stimulants [2]. 1,2,4-triazole derivatives have come to be an important class of heterocyclic compounds in organic creation owing to their therapeutic applications, and there are several drugs including triazole ring in their construction. Among 1,2,4-triazole derivatives, 
mercapto and thione substituted 1,2,4-triazole ring structures have been studied for a range of biological properties. These compounds containing antioxidant [3] in Schiff base triazole has the $\mathrm{C}=\mathrm{S}$ group and the $\mathrm{N}=\mathrm{C}$ group, allowing the ligand to coordinate from the bidentate through thion $(\mathrm{C}=\mathrm{S})$ and $\mathrm{N}$ of azomethine $(\mathrm{N}=\mathrm{CH})$ with metal ions and form stable five-member ring [4]. Structural properties of triazole derivatives, such as reasonable dipole character, hydrogen bonding ability, inflexibility and stability under in vivo environments are the central aims for their greater pharmacological activities [5]. The medicinal uses of some of the drugs containing 1,2,4-triazole nucleus include such as Ribavirin (antiviral; anti-infective), Diniconazole (agriculturefungicide), Itraconazole (antifungal), Bitertanol (fungicide), Triazophos (pesticide), Letrozole (estrogen inhibitor; anti-neoplastic), Diclobutrazol (plant growth regulator), and Rilmazafone (sedative hypnotic) [6]. Fluconazole is used as an antimicrobial drug while vorozole, letrozole and anastrozole are nonsteroidal drugs used for the treatment of cancer, and loreclezole is used as an anticonvulsant [7]. One of the best active approaches used to treat cancers in treatment center is chemotherapy. Though, the lack of choice and development of drug-resistance moderate the ability of cancer chemotherapy. This problem makes it develop to advance new anticancer agents with great potency and less toxicity [8]. Oxidation processes are basic to the energy controlling of wholly living organisms and are kept under exacting controller by several cellular mechanisms [9]. Free radicals arrears are constantly formed in the human body, and unpaired electrons generated can come to be toxic. Great levels of free radicals can cause damage to biomolecules leading to many diseases such as cancer, cardiovascular and autoimmune diseases, aging, and neurodegenerative disorders, through the violent reactivity of the free radicals [10]. To prevent free radical-induced damage, investigation has been focused on the identification of new antioxidants to reduce or neutralize the free radicals, thus shielding the cells from oxidative hurt. Prevalence of cancer has developed to be among the biggest health burdens worldwide, due to which $1 / 6$ (9.6 million) of the total global deaths count occurred in 2018, about $70 \%$ of which were in countries of low or middle levels of income. In terms of frequency of diagnosis, breast cancer occupies almost top rank among all cancer types worldwide, especially in women. In most cases of this type of cancer, the premium management choice is the debunking of the tumour tissue through surgical interference, which is highly associated with recurrence and a not easily managed drug resistance [11]. There are many uses of metallic nanoparticles as they are used in the biomedical field to protect against harmful microorganisms, bioimagnetics, drug transport, cancer treatment, medical diagnostics and antimicrobials, antioxidants, and antimetastasis. At the present time, great importance has given to mineral nanoparticles, which can be used in the industrial field due to its catalytic activity [12]. Cancer remains to be a reason of death in humans worldwide, therefore an important goal is the development of novel drugs for cancer therapy. This study was aimed at synthesizing novel organic compound 4-amino-3-thion-1,2,4triazole derivative, and synthesizing novel micro and nanoparticles complexes in an attempt to investigate if they are suitable as antioxidant compound via reacting with DPPH radicals which loses color stoichometrically as the electrons become paired off. We also compared among the standard antioxidant ascorbic acid with the ligand and complexes (micro and nano), and evaluate their antiprolefrative, and antitubulin activities by targeting tubulin protein, using human breast cancer cell line MCF-7. Our results demonstrated that the macro and nanoparticles novel compounds prevented free radical-induced damage and inhibited MCF-7 cell proliferation with a mechanism of action targeting tubulin. Taken together, the results of the current study indicated that synthetic novel compounds represented new potential agents to be developed for tumour therapy.

\section{Experimental \\ Preparation of thiocarbohydrazide}

Thiocarbohydrazide was prepared; hydrazine hydrate $\mathrm{N}_{2} \mathrm{H}_{4} \cdot \mathrm{H}_{2} \mathrm{O}(0.1 \mathrm{~mol})$ was placed in a round bottom flask and reflux condenser which was equipped with thermometer, well-organized. The temperature was lowered to the range of $10-15^{\circ} \mathrm{C}$ by using ice bath. $0.2 \mathrm{~mol}$ carbon disulfide was added drop wise into the flask while maintaining the temperature under $15^{\circ} \mathrm{C}$; the temperature was then raised progressively to $85^{\circ} \mathrm{C}$ for $90 \mathrm{~min}$. Then the reaction combination was cooled to $10^{\circ} \mathrm{C}$ to obtaine the white precipitate, and was then filtered and washed with distal water as shown in Scheme 1 [13].

Synthesis 4-amino-5-(naphthalen-1-ylmethyl)4H-1,2,4-triazole-3-thiol

A mixture of thiocarbohydrazide $(0.015 \mathrm{~mol})$ and 


$$
\mathrm{N}_{2} \mathrm{H}_{4} \cdot \mathrm{H}_{2} \mathrm{O}+\mathrm{S}=\mathrm{C}=\mathrm{S} \rightarrow \mathrm{S}=\overbrace{\mathrm{NHNH}_{2}}^{\mathrm{CHNH}_{2}}
$$

Scheme 1 Preparation of thiocarbohydrazide.

$\alpha$-naphthal acetic acid $(0.01 \mathrm{~mol})$ were taken in a tube and heated on an oil bath (warmed at the melting temperature) till the content of tube was melted. The product was then left to cool gradually and treated by $5 \% \mathrm{NaHCO}_{3}$ solution to neutralize carboxylic acid if unreacted. The 4-amino-5-(naphthalen-1-ylmethyl)4H-1,2,4-triazole-3-thiol was obtained in good yield, then washed by water, filtrated and was recrystallized with ethanol absolute as shown in Scheme 2 [14].

Synthesis of triazole Schiff base (L1) (4-(((3-mercapto-5-(naphthalen-1-ylmethyl)-4H1,2,4-triazol-4-yl)imino)methyl)phenol)

To a suspension of 4-amino-5-(naphthalen-1ylmethyl)-4H-1,2,4-triazole-3-thiol (0.25 mol) in methanol, an equimolar quantity of 4-hydroxy benzaldehyde was added with 3-4 drops of glacial acetic acid. The reaction mixture was then stirred for $18 \mathrm{~h}$ without heating to avoid gummy product. The precipitate was filtered to obtain Schiff base triazole which was washed with petroleum ether and then recrystallized with ethanol as shown in Scheme 3 [15].

\section{Synthesis of Schiff base complexes}

The methanolic solution of the appropriate metal salt $\left(\mathrm{NiCl}_{2}, \mathrm{PdCl}_{2}\right.$ and $\left.\mathrm{AgNO}_{3}\right)$ was added to a methanolic solution of 4-(((3-mercapto-5-(naphthalen-1-ylmethyl)4H-1,2,4-triazol-4-yl)imino)methyl)phenol (L1) at 1:2 (metal:ligand) ratio and refluxed at $75{ }^{\circ} \mathrm{C}$ for $5 \mathrm{~h}$. The solid was formed after cooling the mixture at room temperature, then filtered, dried and recrystallized from ethanol.

\section{Synthesis of Schiff base nanoparticles and its complexes}

Nanoparticles ligand was synthesized by ultrasound instrument. The methanolic solution of 4-(((3-mercapto-5-(naphthalen-1-ylmethyl)-4H-1,2,4triazol-4yl)imino)methyl)phenol was irradiated with ultrasonic irradiation for $30 \mathrm{~min}$ then mixed with the methanolic solution of the suitable metal salt $\left(\mathrm{NiCl}_{2}, \mathrm{PdCl}_{2}\right.$ and $\left.\mathrm{AgNO}_{3}\right)$ to prepare nanoparticles complexes by ultrasonic method. The suspension was ultrasonically irradiated with a high-density ultrasonic probe inglorious straight into the solution under various conditions. The sonochemical reactions were carried by the sonochemical probe (Ultrasonic Processor UP200S, Hielscher Ultrasound Technology, UK). Sonication time was changed to amplify the optimum condition. The precipitate was formed and filtrated from the liquid then dried at $50{ }^{\circ} \mathrm{C}$ in oven.

\section{DPPH radical scavenging assay}

The antioxidant activity of tested compounds was determined using stable DPPH radicals with minor adjustments to the method described by [16]. The tested novel compounds were evaluated for the DPPH scavenging activities. Each sample was mixed with

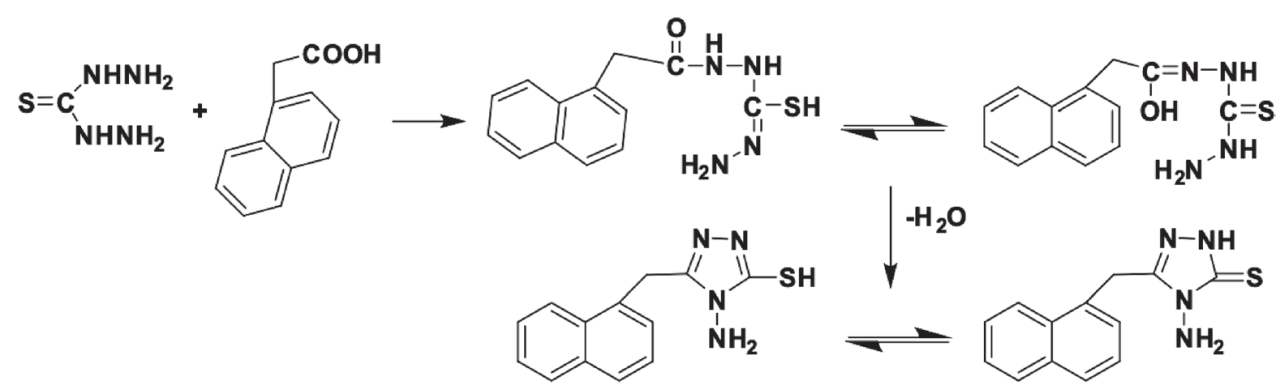

Scheme 2 Synthesis of 4-amino-5-(naphthalen-1-ylmethyl)-4H-1,2,4-triazole-3-thiol.<smiles>Nn1c(Cc2cccc3ccccc23)n[nH]c1=NC=O</smiles>

Scheme 3 Synthesis of triazole Schiff base L1. 
DPPH solution and made up to the required volume using ethanol. The absorbance of the samples was measured at $517 \mathrm{~nm}$. The scavenging activity of the compounds was computed using the formula:

Scavenging $(\%)=($ Absorbance of control Absorbance of sample)/(Absorbance of control) $\times 100$.

\section{MTT assay}

This method was used as described by Ali and her coworkers [17]. Briefly, 96-well microtiter plates containing RPMI medium were used for seeding of the cells $\left(1 \times 10^{5}\right.$ cells $\left./ \mathrm{mL}\right)$. To ensure cell attachment to the wells, they were incubated overnight, and were then treated with tested novel compounds, and then incubated for $72 \mathrm{~h}$. Following washing with phosphatebuffered saline (PBS) for 4 times, they were stained with MTT $(2 \mu \mathrm{g} / \mathrm{mL})$ and incubated for $3 \mathrm{~h}$ at $37{ }^{\circ} \mathrm{C}$. After the incubation time, DMSO was added and the absorption was read (492 nm) using a microplate reader. The equation below was employed to calculate cell growth inhibition rate (cytotoxicity percentage) [18]:

Inhibition rate $(\%)=(\mathrm{A}-\mathrm{B} / \mathrm{A}) \times 100$,

where A is control optical density, and B is sample optical density.

\section{Acridine orange / ethidium bromide (AO/EB) staining}

$\mathrm{AO} / \mathrm{EB}$ staining was performed according to our previously published study [19]. Briefly, novel micro and nanoparticles compounds at $\mathrm{IC}_{50}$ concentration were used to treat the MCF-7 cells in 96-well plates. After incubation for $24 \mathrm{~h}$, washing with PBS 2 times, and added of $100 \mu \mathrm{L}$ of $\mathrm{AO} / \mathrm{EB}$ for $2 \mathrm{~min}$, fluorescence microscopy was applied for cell visualization [20, 21].

\section{Immunofluorescence assay}

MCF-7 cells were treated with novel tested compounds for $24 \mathrm{~h}$. The cells were washed 3 times in PBS, and then fixed with methanol-acetone for 20 min at room temperature. Cells were permeabilized in $0.03 \%$ Triton-X for $30 \mathrm{~min}$ at room temperature. The permeabilized cells were blocked with $10 \%$ normal goat serum for $1 \mathrm{~h}$ at room temperature. The antitubulin antibody at concentration $1 \mu \mathrm{g} / \mathrm{mL}$ was added to the cells for $24 \mathrm{~h}$ at $4{ }^{\circ} \mathrm{C}$. Cells were washed as mentioned above, after washing. Alexa Fluor 488-conjugated goat anti-rabbit IgG or $1 \mu \mathrm{g} / \mathrm{mL}$ of the secondary antibody was added for $2 \mathrm{~h}$ at room temperature. The cells were washed with PBS, and viewed using a fluorescent microscope [22].

\section{Statistical analysis}

The data represented as mean \pm SEM were analyzed using GraphPad Prism 5 (GraphPad Software, USA) and statistically significant differences as tested by unpaired t-test were set at a probability level of *p < 0.05 [23].

\section{Results and Discussion Physical properties of ligand and its metal complexes}

The Elemental analyses and physical properties of the synthesis ligand of triazole Schiff base and its metal complexes are showed in Table 1 (top panel). Triazole Schiff bases L1 complexes were synthesized in a powder. All complexes were stable in air; they were soluble in dimethylformamide (DMF) and dimethyl sulfoxide (DMSO), but insoluble in other organic solvents. Elemental analysis suggested that the molar ratios for all complexes were 1:2 (metal: ligand).

\section{Mass spectrum}

The mass spectrum of the ligand (L) showed a mass to charge ratio $204 \mathrm{M} / \mathrm{Z}$ of $100 \%$ relative abundance and $360 \mathrm{M} / \mathrm{Z}$ of $40 \%$ abundance, which was evidence that the compound was prepared. The mass spectrum are shown in Fig. 1.

Electronic spectra, conductivity measurements and magnetic susceptibility

The ultraviolet-visible spectroscopy (UV-Vis) absorption spectrum of ligand L1 showed two bands at $295 \mathrm{~nm}, 33898 \mathrm{~cm}^{-1}$ and $308 \mathrm{~nm}, 32468 \mathrm{~cm}^{-1}$, allocated to $\pi \rightarrow \pi^{*}$ and $n \rightarrow \pi^{*}$ transitions [24]. The spectroscopic data for complexation of L1 with metal ions presented new bands in the UV-Vis, recognized as a metal ligand charge transfer (MLCT) and to the transitions of ligand field. The spectroscopic data for each ligand and complexes are showed maximum absorption in Table 1 (middle panel).

The spectrum of complex $\mathrm{L} 1 \mathrm{Ni}$ in $\mathrm{CHCl}_{3}$ showed two spin-allowed $680 \mathrm{~nm}, 14706 \mathrm{~cm}^{-1}$ and $455 \mathrm{~nm}$, $21780 \mathrm{~cm}^{-1}$, allocated to ${ }^{3} \mathrm{~A}_{2} \mathrm{~g} \rightarrow{ }^{3} \mathrm{~T}_{1} \mathrm{~g}(\mathrm{~F})\left(\mathrm{v}_{2}\right)$ and ${ }^{3} \mathrm{~A}_{2} \mathrm{~g} \rightarrow{ }^{3} \mathrm{~T}_{1} \mathrm{~g}(\mathrm{P})\left(v_{3}\right)$ transitions, respectively $[25,26]$. This indicated geometry was octahedral for $\mathrm{Ni}(\mathrm{II})$ ion. The value of $\left(v_{1}\right)$ was calculated, as of $11781 \mathrm{~cm}^{-1}$ and accredited to ${ }^{3} \mathrm{~A}_{2} \mathrm{~g} \rightarrow{ }^{3} \mathrm{~T}_{2} \mathrm{~g}(\mathrm{~F})$ transition [15]. The magnetic value for $\mathrm{Ni}$ (II) was observed at $2.88 \mathrm{BM}$ and it was about the range of 2.8 - 3.5 BM [27], which approved the octahedral geometry of $\mathrm{Ni}(\mathrm{II})$ ion. The 


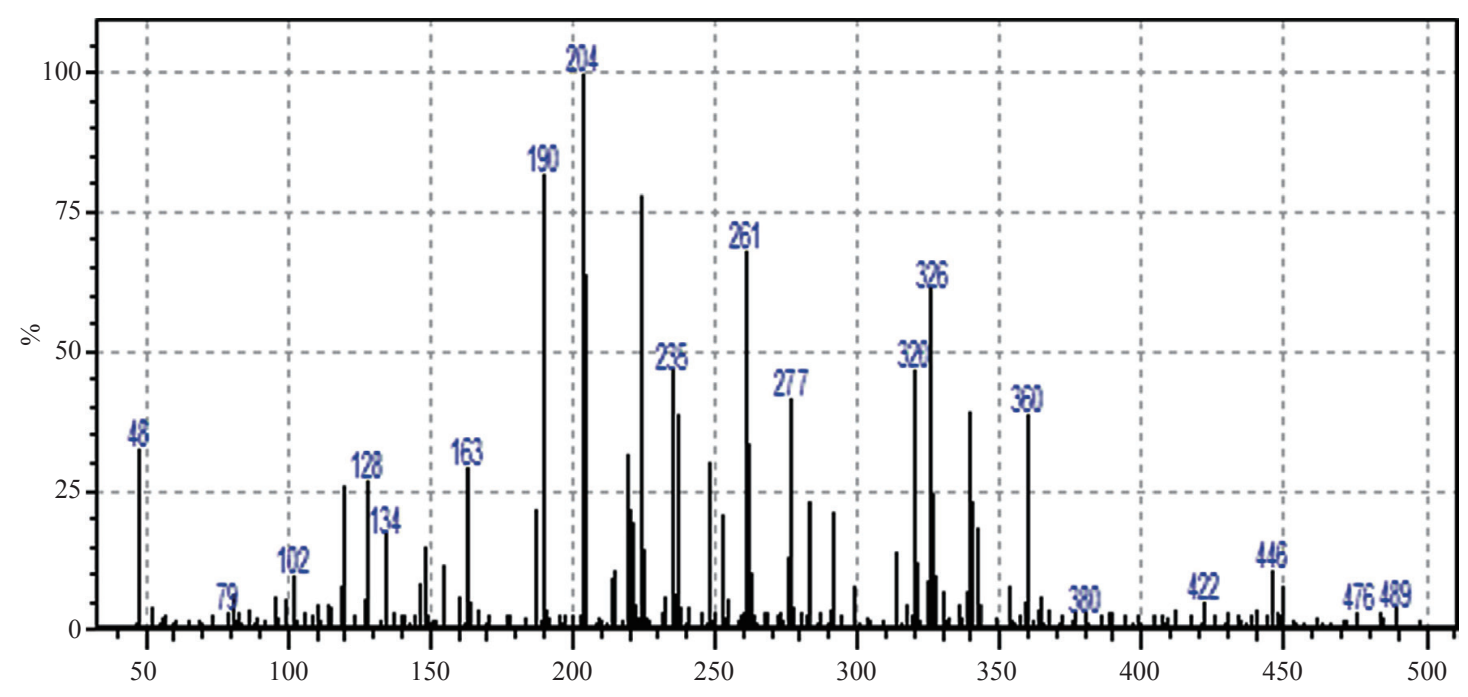

Fig. 1 Mass spectrum for ligand L1.

conductivity referred to the non-ionic performance of this complex. The spectrum of L1 Ag complex didn't have the $d$ - $d$ transition according to $d^{10}$. The prepared complex was diamagnetic. The electronic spectrum for $\mathrm{L} 1 \mathrm{Ag}$ in $\mathrm{CHCl}_{3}$, exhibited three bands at $288 \mathrm{~nm}$, $34722 \mathrm{~cm}^{-1}, 300 \mathrm{~nm}, 33333 \mathrm{~cm}^{-1}$ and $345 \mathrm{~nm}, 28986$ $\mathrm{cm}^{-1}$, assigned to $\pi \rightarrow \pi^{*}, \mathrm{n} \rightarrow \pi^{*}$ and $\mathrm{Ag} \rightarrow \mathrm{L}_{\mathrm{CT}}$ transitions respectively $[28,29]$. The conducting manner signalized ionic for L1 Ag. The UV-Vis spectrum of L1 Pd complex, displayed two spin-allowed at 465 $\mathrm{nm}, 21505 \mathrm{~cm}^{-1}, 398 \mathrm{~nm}, 25126 \mathrm{~cm}^{-1}$, assigned to ${ }^{1} \mathrm{~A}_{1} \mathrm{~g} \rightarrow{ }^{1} \mathrm{~B}_{1} \mathrm{~g}$ and ${ }^{1} \mathrm{~A}_{1} \mathrm{~g} \rightarrow{ }^{1} \mathrm{Eg}$ transitions respectively [30]. The complex might have coordination of the central metal ion which was square-planar. The magnetic numbers of Pd ion pointed to diamagnetic complex. This approvesd the square-planar geometry of round $\operatorname{Pd}(\mathrm{II})$ ion [31], and the complex ionic attitude in the conductance measurements.

\section{Fourier-transform infrared spectroscopy (FTIR) for the free ligand (L) and its complexes}

The FTIR spectrum of L1 ligand exhibited the distinctive stretching vibration bands at the posterior frequency with their identical assignments to the $\mathrm{NH}$ group at 3188,1693 and $1635 \mathrm{~cm}^{-1}$ to the $\mathrm{C}=\mathrm{N}$ group, 881 and $1024 \mathrm{~cm}^{-1}$ to the $\mathrm{C}=\mathrm{S}$ group, 3440 and 3380 $\mathrm{cm}^{-1}$ to the $\mathrm{O}-\mathrm{H}$ phenol, $1230 \mathrm{~cm}^{-1}$ to the O-C group, and $2767 \mathrm{~cm}^{-1}$ to $\mathrm{S}-\mathrm{H}$. It was observed that thiolthione tautomerism existed in the ligand spectrum [24, 32]. The ligand bound with metal ion at nitrogen of azomethine and sulfur of thion group to make stable 5 membered chelate ring [8]. The significant stretching vibrations of LI and its complexes are listed in Table 1 (lower panel). The stretching modes for L1 Ni, L1 Ag and $\mathrm{L} 1 \mathrm{Pd}$ exhibited the shift of $\mathrm{C}=\mathrm{N}$ groups to lower frequencies, which indicated coordination of the metal ion with the ligand via $\mathrm{N}$ of azomethain groups. The spectra of complexes showed new band vibrational modes to $\mathrm{M}-\mathrm{N}, \mathrm{M}-\mathrm{S}$ and $\mathrm{M}-\mathrm{Cl}$ groups frequencies as a result of bonding metal ion with ligand $[25,26]$. The spectra of nano ligand and its nanopartical complexes showed the same behaviour. The important stretching vibrations are listed in Table 1 (lower panel), and the FTIR spectra are shown in Fig. 2.

\section{Nuclear magnetic resonance $\left({ }^{1} \mathrm{H}\right.$ NMR and ${ }^{13} \mathrm{C}$ NMR) spectra of ligand L1}

${ }^{1} \mathrm{H}$ NMR spectrum of compound L1 in DMSO-d6 peak assignments was characterized by the presence of $\mathrm{N}=\mathrm{CH}$ azomethine group with the signal appearing at $\delta 9.77 \mathrm{ppm}$. It also exhibited signal at $\delta 6.82$ $8.23 \mathrm{ppm}$ belonging to aromatic protons, and at $\delta$ $9.55 \mathrm{ppm}$ owing to $\mathrm{O}-\mathrm{H}$ phenolic proton. $\mathrm{CH}_{2}$ protons appeared at $\delta 4.59 \mathrm{ppm}$, while those of the $\mathrm{S}-\mathrm{H}$ group exhibited a peak at $\delta 13.6 \mathrm{ppm}$, although the signal of SH protons was very weak as recorded in ${ }^{1} \mathrm{H}-\mathrm{NMR}$, and it was observed that the thiol-thione tautomerism existed in the ligand spectrum [27, 30-37]. ${ }^{13} \mathrm{C}$ NMR spectra of the L1 peaks assignments of chemical shifts were characterized by the peak associated to $\delta \mathrm{N}=\mathrm{C}$ at $\delta 151.6 \mathrm{ppm}$, assigned to the group of azomethine. In addition, the aromatic carbon rings exhibited chemical shifts in the range of $\delta 116-133.8 \mathrm{ppm}$. The spectra performed broad peaks at lower fields at $\delta 159.2 \mathrm{ppm}$, and were allocated to the $\mathrm{N}-\mathrm{C}=\mathrm{S} / \mathrm{C}-\mathrm{S}$ thion/thiole group. Chemical shifts at $\delta 162 \mathrm{ppm}$ were assigned to 
Table 1 Physical properties of the synthesized complexes (top panel). Electronic spectra, spectral parameters, molar conductivity, effective magnetic moments ( $\mu$ eff) (middle panel). Infrared Spectra vibrations $\left(\mathrm{cm}^{-1}\right)$ for the ligand (L1) and their metal complexes (lower panel)

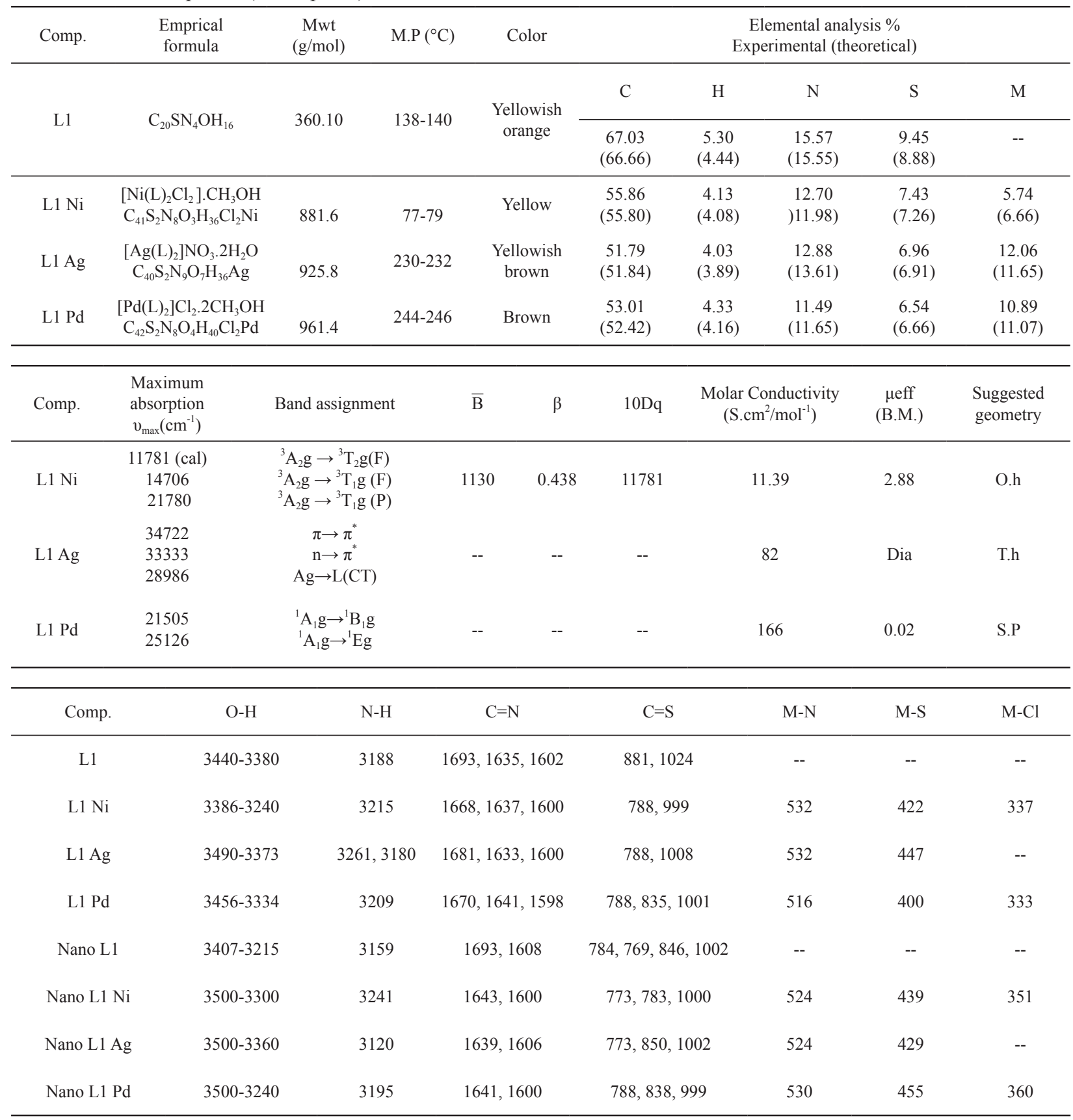

C-O, while those of the $\mathrm{CH}_{2}$ group appeared at $\delta 28.7$ $[35,36]$. The NMR spectra of the ligand are shown in Fig. 3, and the suggested geometry structure for micro complexes is shown in Fig. 4.

\section{Structural properties of a novel nanoparticles using X-ray diffraction (XRD), atomic force microscopy (AFM), and scanning electron microscopy (SEM)}

The XRD patterns of nanoparticles complexes are shown in Fig. 5, containing one main peak at diffraction angles $22^{\circ}, 27.72^{\circ}$ and $23.1^{\circ}$ for nano L1 $\mathrm{Ni}$, nano L1 Ag and nano L1 Pd, respectively. The $2 \theta$ and crystal size (D) were calculated and showed in Table 2 (top panel). The nanoparticles complexes L1 Ni, L1 Ag and L1 Pd had semi ball-shape with perfect dispensability, identical grains and were aligned perpendicularly. The estimated values of average grain size and the root mean square (RMS) of average surface roughness were calculated by using special 

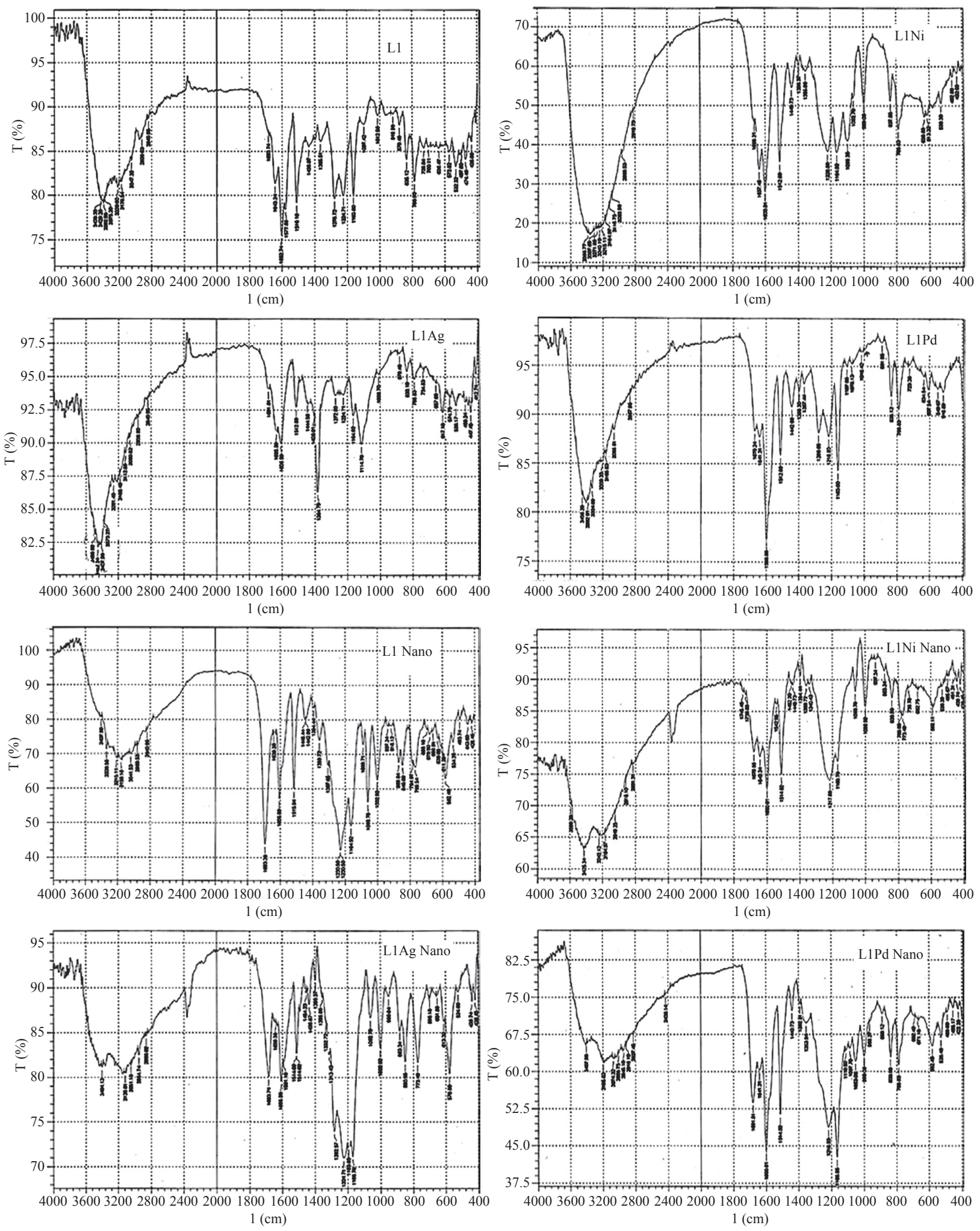

Fig. 2 FTIR spectra of the ligand L1, macro complexes (L1 Ni, L1 Ag and L1 Pd), and nano complexes (L1 Ni, L1 Ag and L1 Pd).

software and are listed in Table 2 (lower panel). The nanoparticles complexes (nano L1 Ni, nano L1 Ag and nano L1 Pd) were conglomerate to form larger particles of 71.18, 91.29 and $75.74 \mathrm{~nm}$ respectively. The 3D AFM images and granularity growth distribution chart of nanoparticles complexes (nano L1 Ni, nano L1 Ag and nano L1 Pd) are shown in Fig. 5. SEM images of the nanoparticles complexes (nano L1 Ni, nano L1 Ag and nano L1 Pd) are shown in Fig. 6. SEM images enhanced the diverse morphology of these 


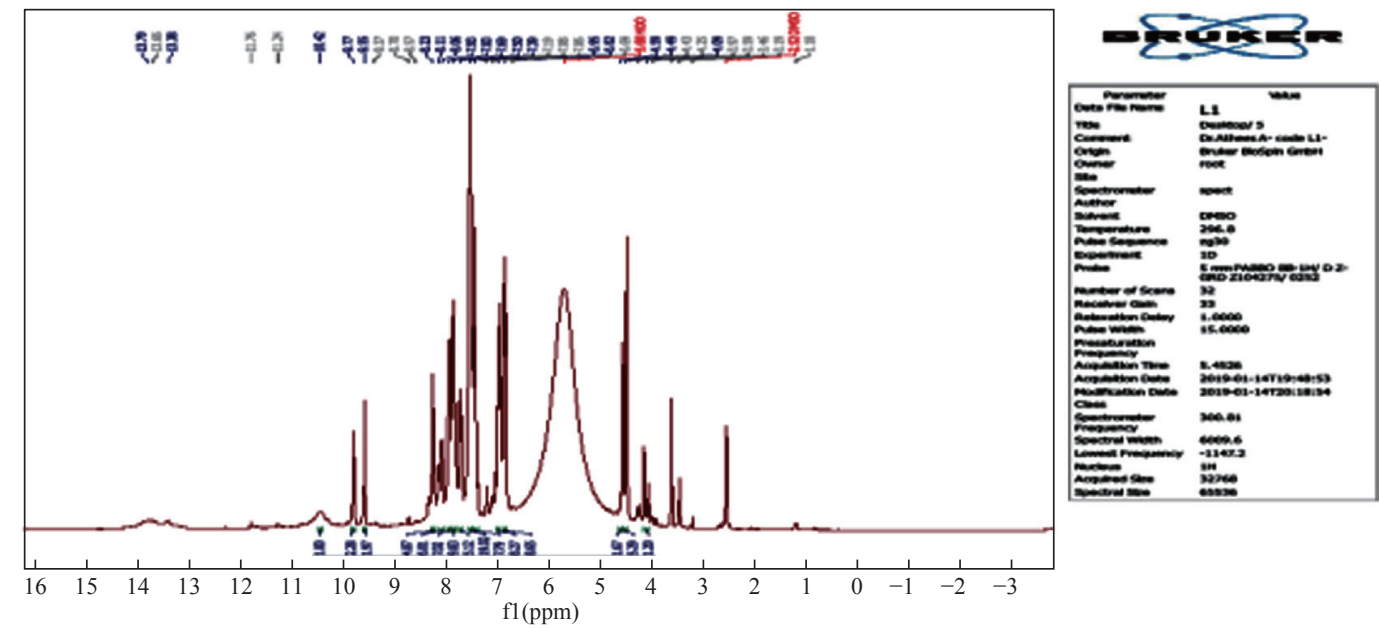

${ }^{1}$ HNMR spectrum for the ligand L1

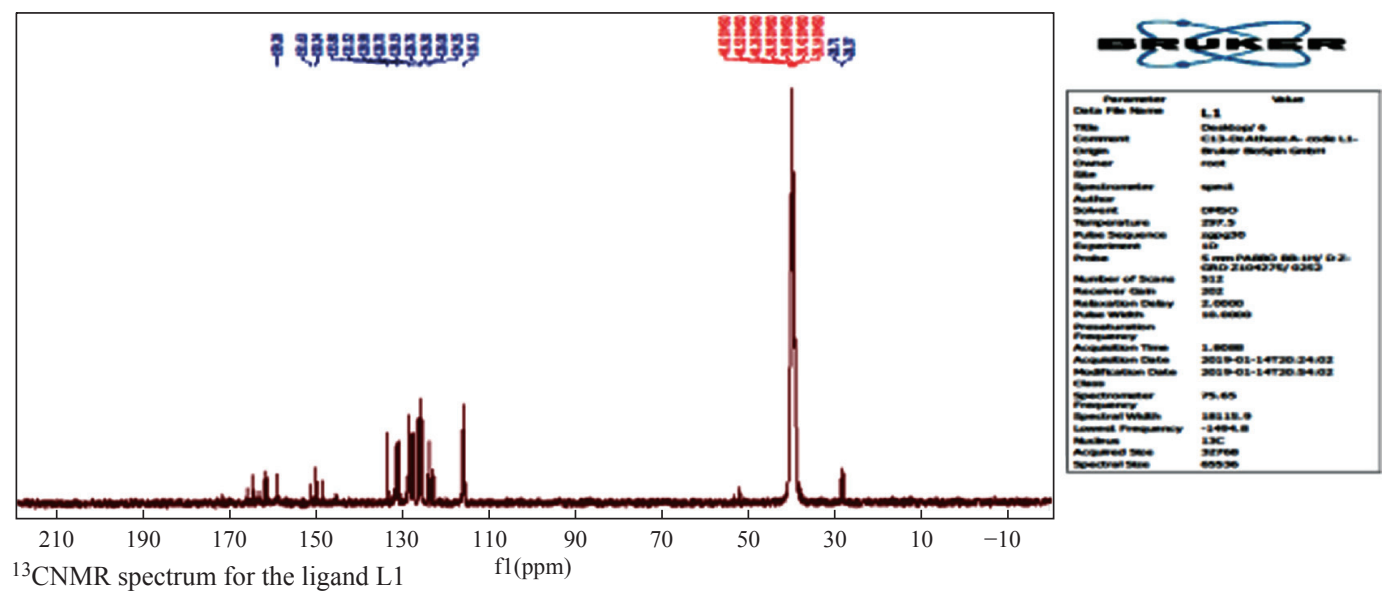

Fig. 3 NMR spectra for the ligand L1.

Table 2 The crystallite size (D) and $2 \theta\left(^{\circ}\right)$ of nanoparticles complexes (nano L1 Ni, nano L1 Ag and nano L1 Pd) (top panel). The grain size, roughness average and root mean square of nanoparticle complexes (nano L1 Ni, nano L1 Ag and nano L1 Pd) (lower panel)

\begin{tabular}{cccc}
\hline Nano complexes & $2 \theta\left(^{\circ}\right)$ & $\beta\left(^{\circ}\right)$ & $\mathrm{D}(\mathrm{nm})$ \\
\hline Nano L1 Ni & 22 & 10 & 0.84829 \\
Nano L1 Ag & 27.72 & 1.39 & 6.170323 \\
Nano L1 Pd & 23.1 & 2.58 & 3.294242 \\
\hline Nano sample & Avg. diameter $(\mathrm{nm})$ & Avg. roughness $(\mathrm{nm})$ & Root mean square $(\mathrm{nm})$ \\
\hline Nano L1 Ni & 71.18 & 0.674 & 0.733 \\
Nano L1 Ag & 91.29 & 0.745 & 0.872 \\
Nano L1 Pd & 75.74 & 13.3 & 15.4 \\
\hline
\end{tabular}

nanoparticles, showing that they were not symmetric and consisted of many small irregular nanoparticles, looking like ball shapes with average size ranging from 42.32 - $79.65 \mathrm{~nm}$ for nano L1 Ni, but looking like rock shapes for nano L1 Ag with average size ranging from $20.35-54.79 \mathrm{~nm}$. On the other hand, the shape of nano
L1 Pd was like worm with length of about $200 \mathrm{~nm}$ and head size of $53.3 \mathrm{~nm}$.

\section{DPPH radical scavenging assay}

DPPH has stable free radicals which are associated with spare electrons. Free radicals of DPPH delocalized 

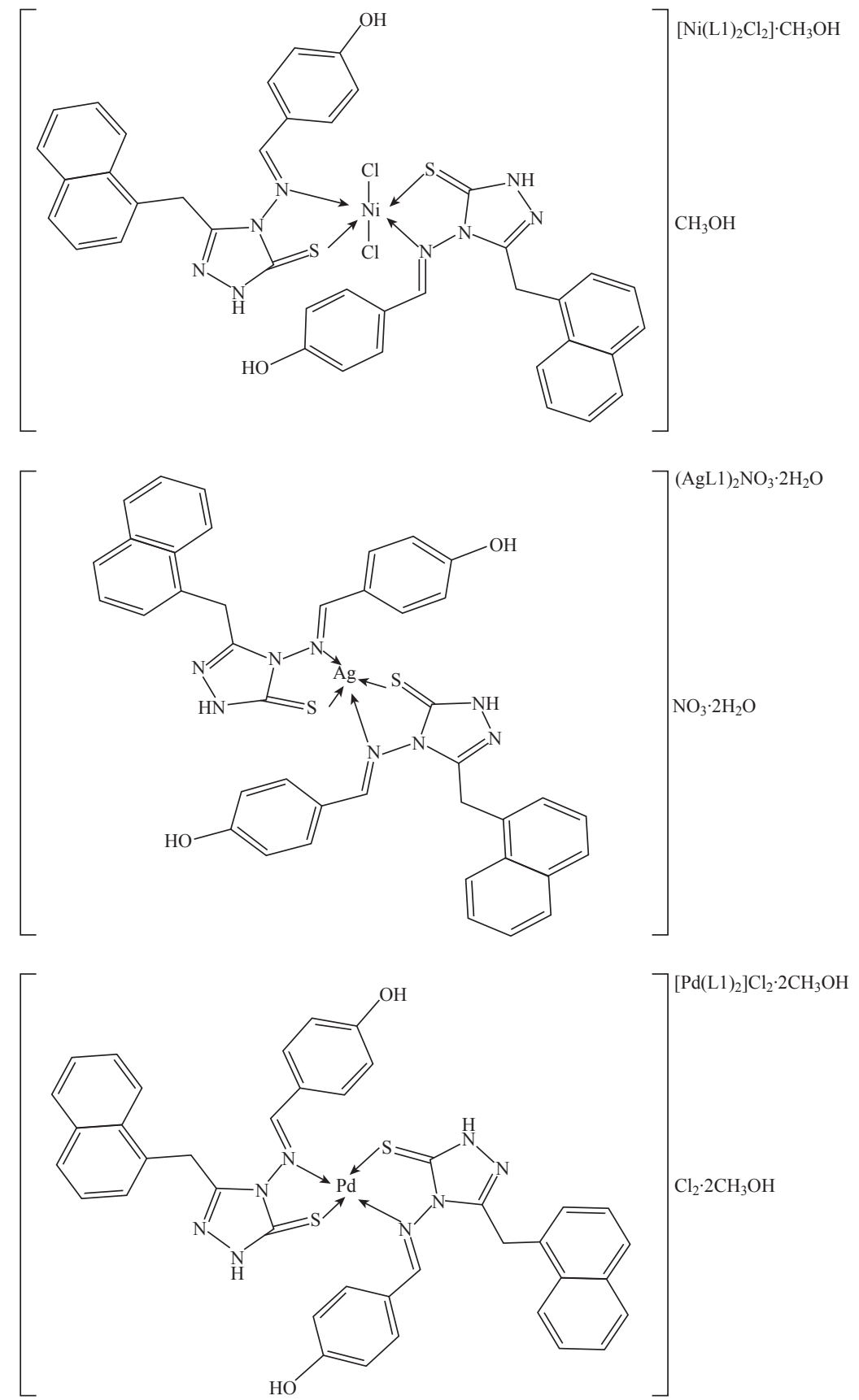

Fig. 4 Structural geometry of micro complexes.

over the entire molecule, barring its dimerization characterized by an absorption band at $517 \mathrm{~nm}$. While a solution of DPPH can blend with a substrate that can donate a hydrogen atom, this may give an upward push to the reduced form with a color change from violet to yellow [10]. The DPPH radical scavenging (\%) activity of the tested novel compounds is shown in Fig. 7. The result revealed that the tested compounds could donate hydrogen atoms and remove the unstable electron from DPPH and could be useful for the management of numerous deleterious diseases.

\section{Anti-proliferative activity of novel tested compounds}

As shown in Fig. 8(a), the viability of MCF-7 cells was reduced after being treated with tested compounds in all used concentrations and was of concentration dependent manner. Moreover, the present study also tested the morphological effects of the treatments on cancer cell lines using crystal violet stain (Fig. 8(b)). After incubation with tested compounds at $\mathrm{IC}_{50}$, cell imaging demonstrated extensive cellular morphological changes, as well as clumping and inhibition of the 
(a)
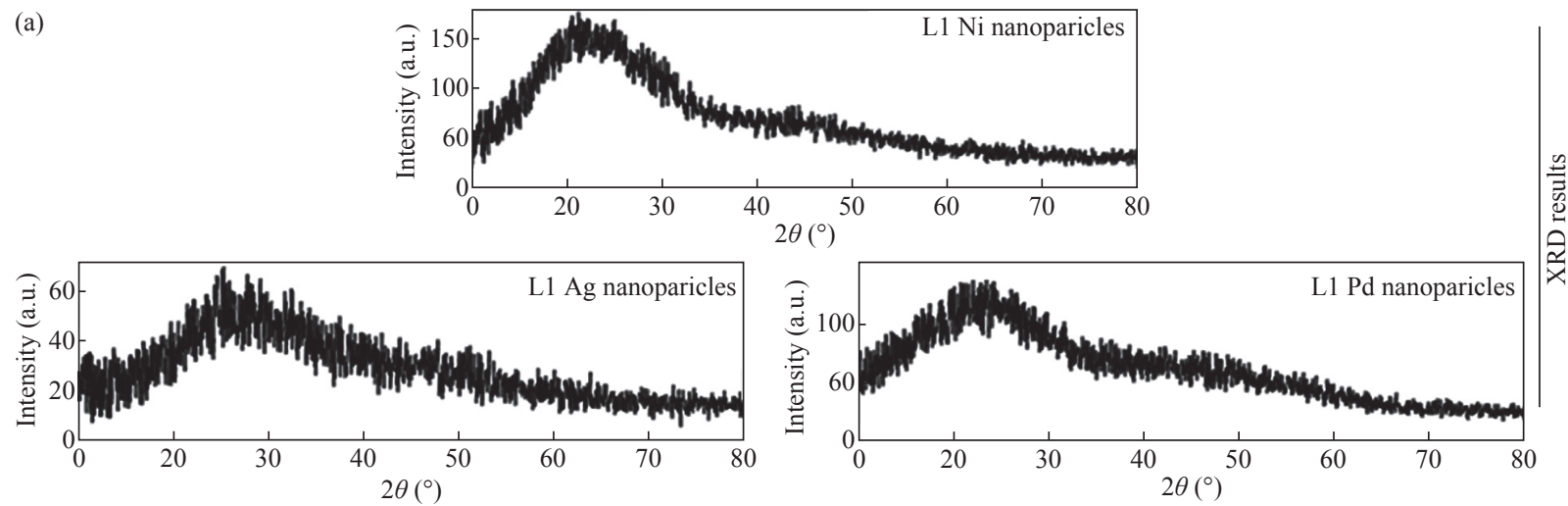

(b)
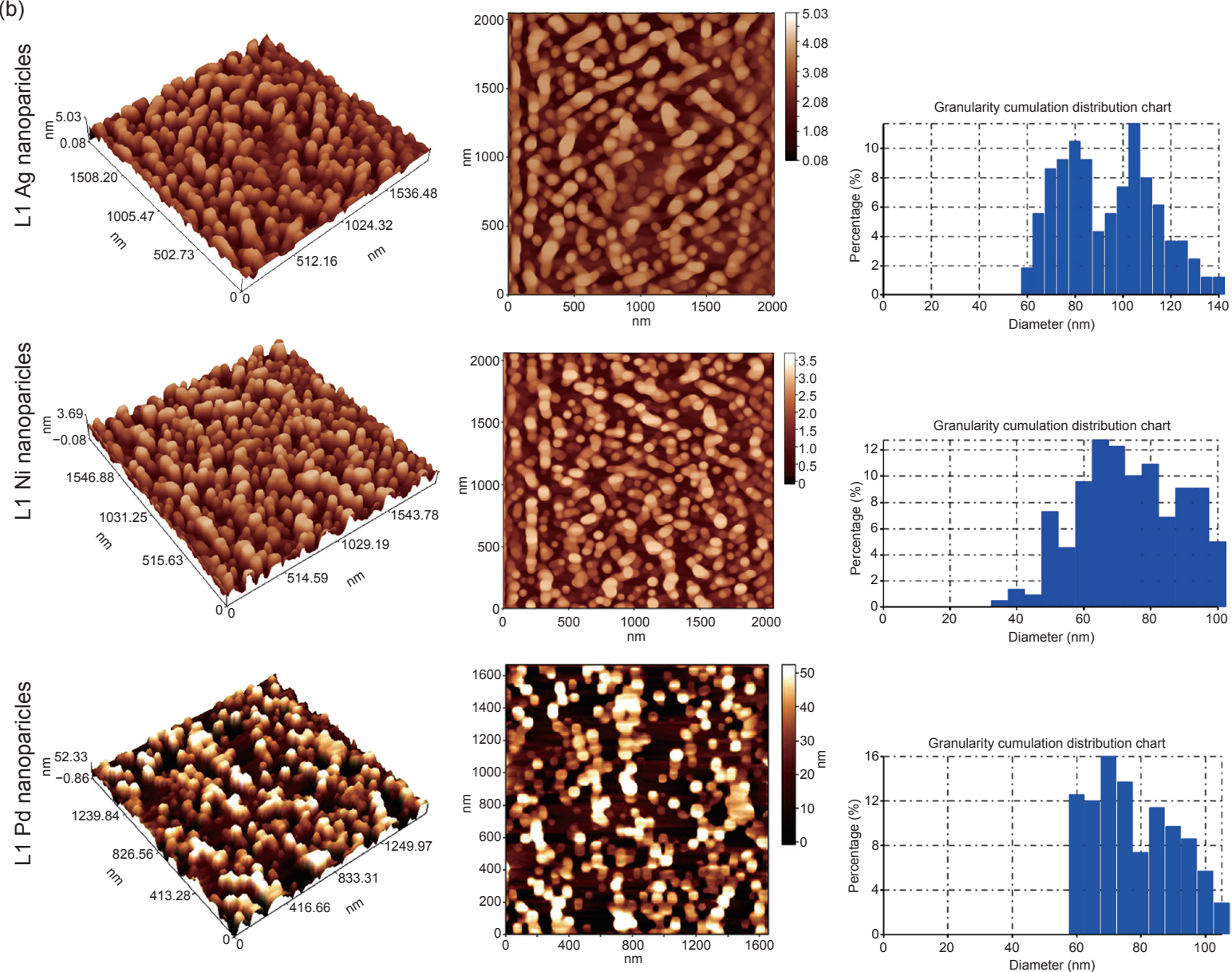

Fig. 5 (a) XRD of nanoparticles complexes; (b) AFM of nanoparticles complexes.

communication of the cells. However, such alterations were not seen in the control group.

\section{Role of tested compounds in induction of apoptosis}

With the aim of further examining the ability of tested compounds, to induce death of cancer cell lines, a combination of acridine orange-ethidium bromide dyes was used Fig. 9. In this assay, the structure of the nuclei of the cells was observed to be intact, with a stable bright green color. The membranes of cancer cells treated with tested compounds showed less integrity in comparison to the membranes of the untreated cells. Apoptotic cells commonly showed nuclei that were characterized by red to green color while the condensation of their chromatin varied in level. The morphological alterations in the treated MCF-7 cells suggested that the observed cell death was 

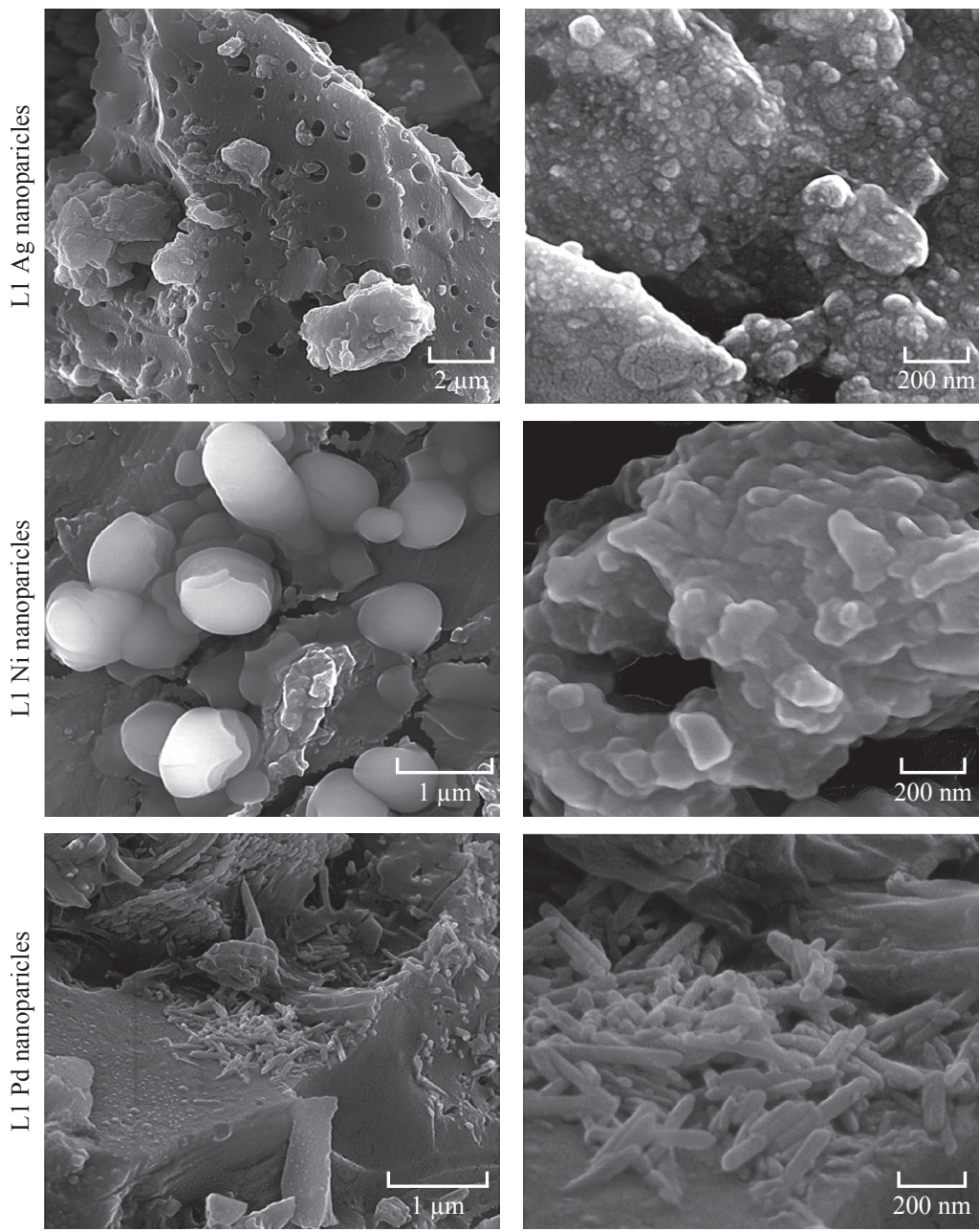

Fig. 6 SEM images of novel nanoparticles complexes.
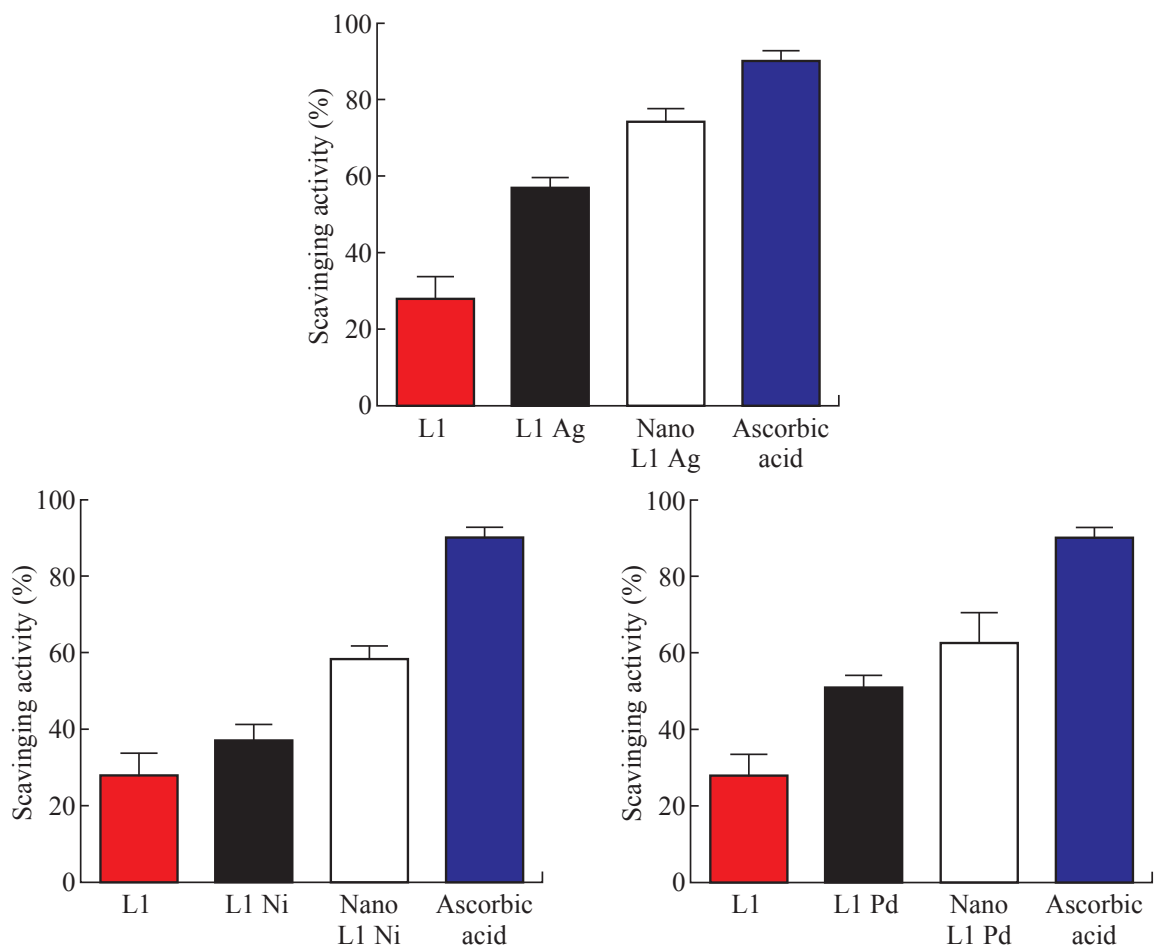

Fig. 7 Antioxidant activity of micro and nanoparticles complexes. 
(a)
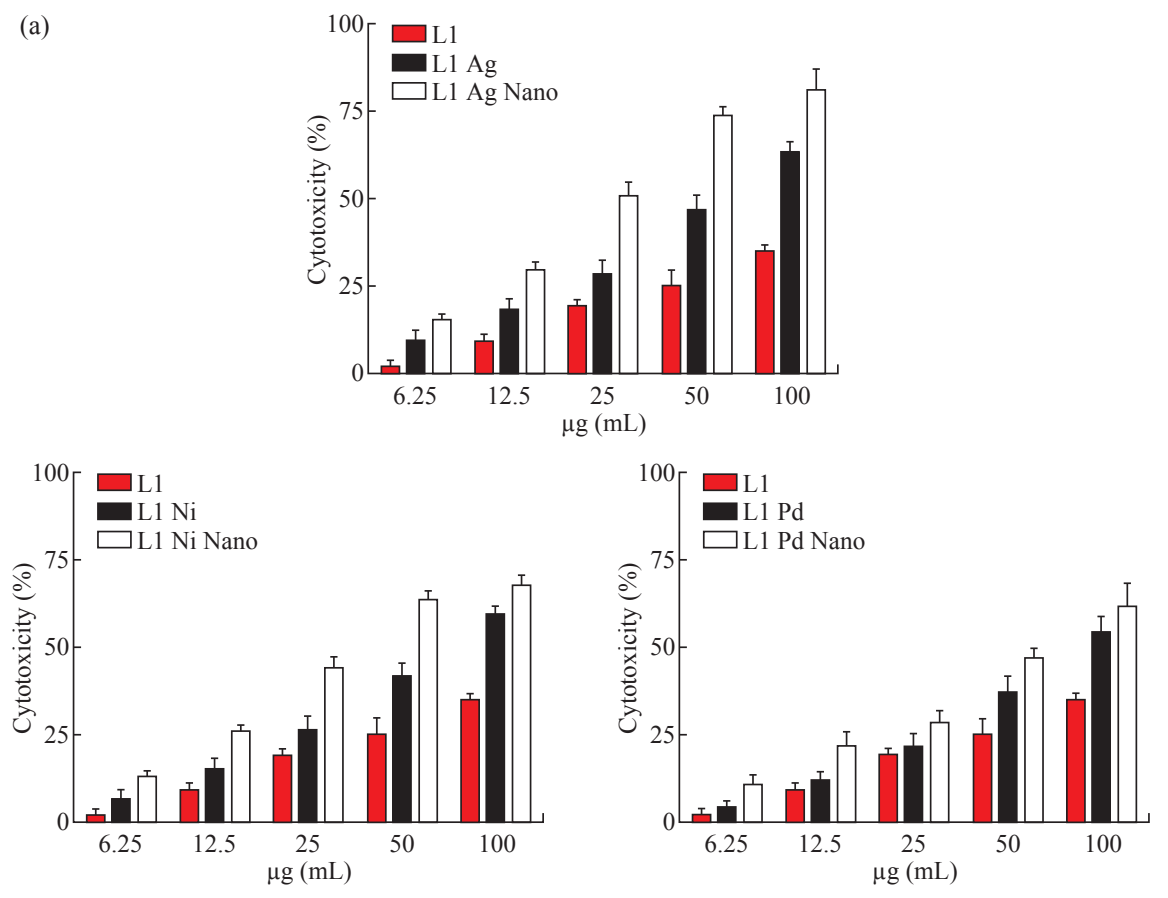

(b)
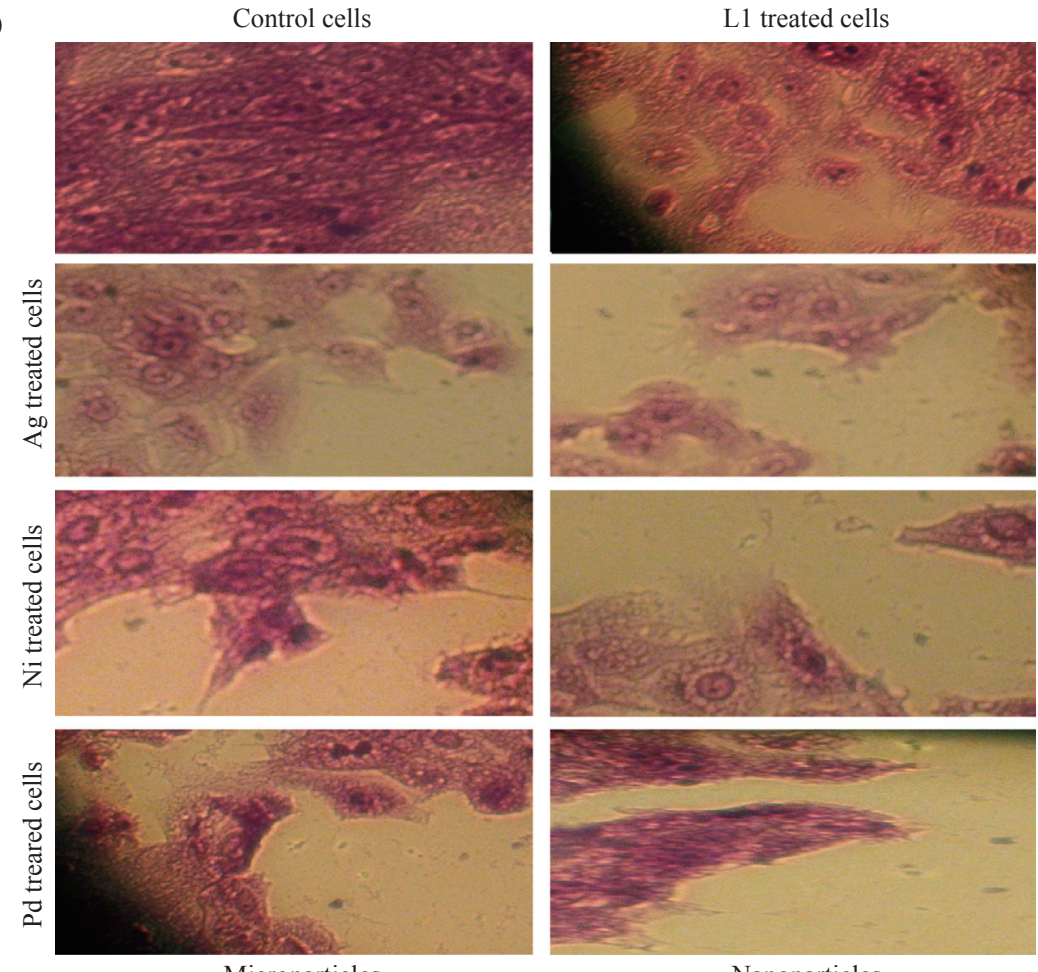

Microparticles

Nanoparticles

Fig. 8 Anti-proliferative activity of micro and nanoparticles complexes against MCF-7 cells.

caused by apoptosis.

\section{Inhibition of tubulin}

To confirm the direct effects of tested novel micro and nanoparticles compounds on tubulin, the current study tested the changes and alterations in the microtubule network induced by tested novel compounds. As shown in Fig. 10, the tubulin network in MCF-7 cells without treating showed normal arrangement and organization, whereas treated MCF-7 cells with tested novel compounds at $\mathrm{IC}_{50}$ concentrations showed abnormal arrangement of tubulin. The results demonstrated that microtubules became short and wrapped around the nucleus in MCF- 

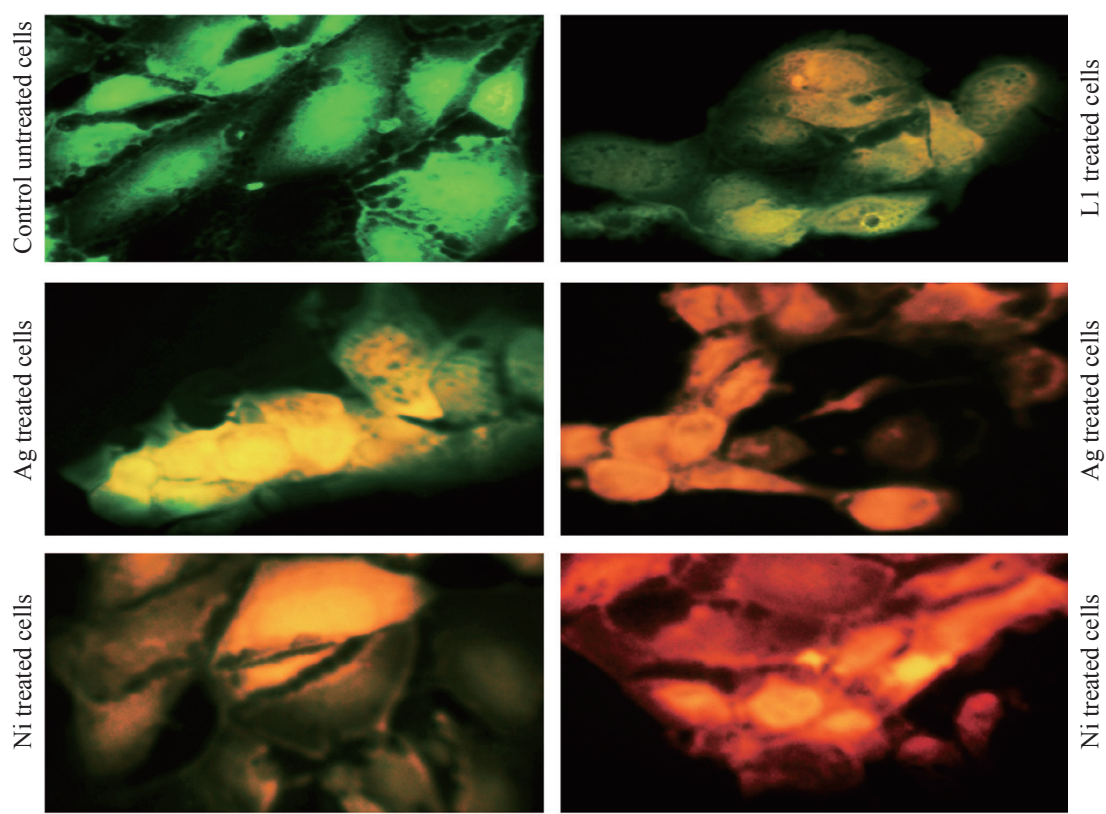

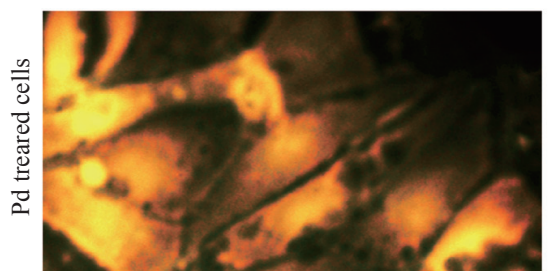

Microparticles

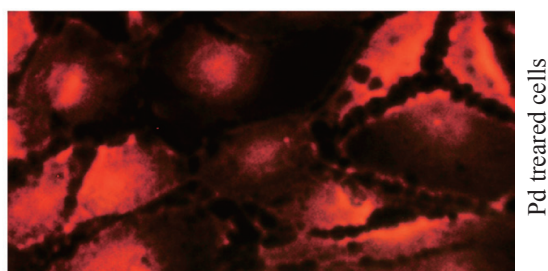

Nanoparticles

Fig. 9 Micro and nanoparticles complexes induced apoptosis in MCF-7 cells.
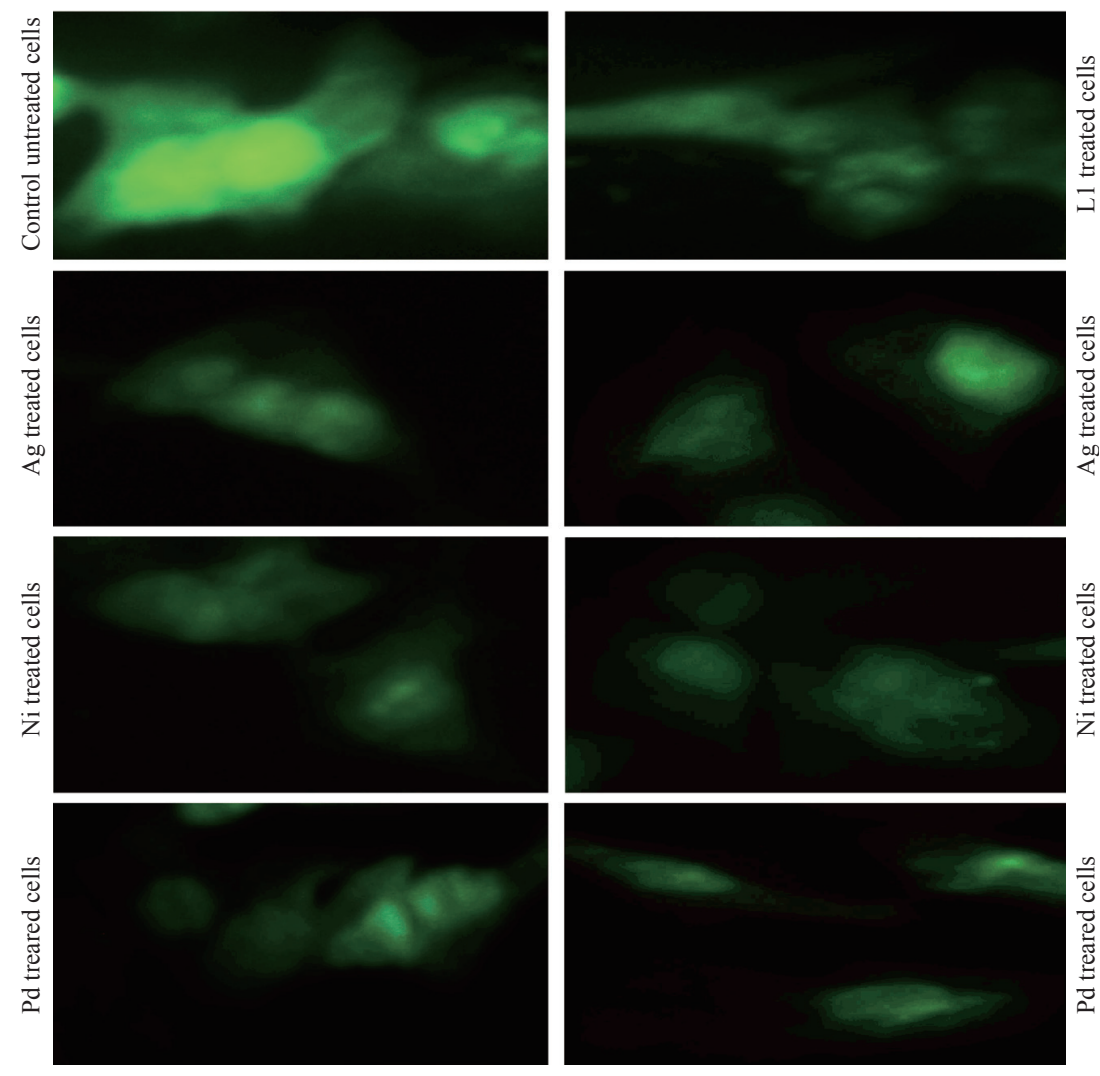

Microparticles

Nanoparticles

Fig. 10 Tubulin targeted by micro and nanoparticles complexes in MCF-7 cells. 
7 cells that were treated with novel tested compounds in comparison with the untreated control cells.

\section{Conclusions}

Novel micro and nanoparticles complexes were prepared in this study. These novel compounds showed potent anti-proliferative activity against MCF-7 cells at low concentration. Consistent with its potent antiproliferative activity, novel compounds also displayed excellent anti-tubulin activity against breast cancer cells with an $\mathrm{IC}_{50}$ value. Our results suggested that a novel synthetic compound might be a potential tubulin inhibitor.

\section{Conflict of interest}

The authors declare that no competing interest exists.

\section{References}

[1] N. Seelam, S.P. Shrivastava., S. Prasanthi, et al., Synthesis and in vitro study of some fused 1,2,4-triazole derivatives as antimycobacterial agents. Journal of Saudi Chemical Society, 2016, 20(4): 411-418.

[2] C. Tratrat, M. Haroun, A. Paparisva, et al., Design, synthesis and biological evaluation of new substituted 5-benzylideno-2-adamantylthiazol [3,2-b][1,2,4] triazol-6 $(5 \mathrm{H})$ ones. Pharmacophore models for antifungal activity. Arabian Journal of Chemistry, 2018, 11(4): 573590.

[3] C. Kus, G. Ayhan-Kılcıgil, S. Özbey, et al., Synthesis and antioxidant properties of novel N-methyl-1,3,4-thiadiazol2-amine and 4-methyl-2H-1,2,4-triazole-3 (4H)-thione derivatives of benzimidazole class. Bioorganic \& Medicinal Chemistry, 2008, 16(8), 4294-4303.

[4] Ali, A.A., \& Al-Abdali, B. I. (2015). Synthesis and characterization of 4-(((3-mercapto-5-phenyl-4H-1,2,4triazole-4-yl) imino) methyl)-2-methoxyphenol and its complexes with $\mathrm{Zr}$ (IV), Cd (II) and Sn (II) ions. Iraqi Journal of Science, 56(2B), 1274-1288.

[5] Stefanska, J., Szulczyk, D., Koziol, A.E., Miroslaw, B., Kedzierska, E., Fidecka, S., ...\&Struga, M. (2012). Disubstitutedthiourea derivatives and their activity on CNS: Synthesis and biological evaluation. European journal of medicinal chemistry, 55, 205-213. https://doi. org/10.1016/j.ejmech.2012.07.020

[6] Singh, A.K., \& Kandel, K.R. (2012). Synthesis of Triazole derivative:[4-(benzylideneamino)-5-phenyl-4H-1,2,4triazole-3-thiol]. Journal of Nepal Chemical Society, 30, 174-177.

[7] Bekircan, O., \& Bektas, H. (2006). Synthesis of new bis1, 2, 4-triazole derivatives. Molecules , 11(6), 469-477.

[8] Wu, Q., Yang, Z., Nie, Y., Shi, Y., \& Fan, D. (2014). Multi-drug resistance in cancer chemotherapeutics: mechanisms and lab approaches. Cancer letters, 347(2), 159-166.

[9] Ślusarczyk, S., Hajnos, M., Skalicka-Woźniak, K., \& Matkowski, A. (2009). Antioxidant activity of polyphenols from Lycopuslucidus Turcz. Food Chemistry, 113(1), 134138.

[10] N. Karal, Ö. Güzel, N. Özsoy, et al., Synthesis of new spiroindolinones incorporating a benzothiazole moiety as antioxidant agents. European Journal of Medicinal Chemistry, 2010, 45(3): 1068-1077.

[11] F. Bray, J. Ferlay, I. Soerjomataram, et al., Global cancer statistics 2018: GLOBOCAN estimates of incidence and mortality worldwide for 36 cancers in 185 countries. $C A$ Cancer J Clin, 2018, 68: 394-424.

[12] A. Schrofel, G. Kratosova, I. Safarik, et al., Applications of biosynthesized metallic nanoparticles - A re-view. Acta Biomaterialia, 2014, 10: 4023-4042.

[13] J. Zhou, D. Wu, and D. Guo, Optimization of the production of thiocarbohydrazide using the Taguchi method. Journal of Chemical Technology \& Biotechnology, 2010, 85(10): 1402-1406.

[14] A.Y. Hassan, Synthesis and reactions of new fused heterocycles derived from 5-substituted-4-amino3-mercapto-(4H)-1,2,4-triazole with biological interest. Phosphorus, Sulfur, and Silicon, 2009, 184(11): 2759-2776.

[15] Z. Li, Z. Gu, K. Yin, et al., Synthesis of substitutedphenyl-1,2,4-triazol-3-thione analogues with modified d-glucopyranosyl residues and their antiproliferative activities. European Journal of Medicinal Chemistry, 2009, 44(11): 4716-4720.

[16] M.S. Jabir, A.A. Taha, and U.I. Sahib, Linalool loaded on glutathione-modified gold nanoparticles: a drug delivery system for a successful antimicrobial therapy. Artif. Cells, Nanomedicine Biotechnol, 2018.

[17] S.H. Ali, G.M. Sulaiman, M.M. Al-Halbosiy, et al., Fabrication of hesperidin nanoparticles loaded by poly lactic co-Glycolic acid for improved therapeutic efficiency and cytotoxicity. Artificial Cells, Nanomedicine, and Biotechnology, 2019, 47(1): 378-394.

[18] H.A. Kadhem, S.A. Ibraheem, M.S. Jabir, et al., Zinc oxide nanoparticles induces apoptosis in human breast cancer cells via Caspase- 8 and P53 pathway, Nano Biomed. Eng., 2019, 1: 35-43.

[19] I. Alsaedi, Z.J. Taqi, A Hussien, et al., Graphene nanoparticles induces apoptosis in MCF-7 cells through mitochondrial damage and NF-KB pathway. Materials Research Express, 2019, 6: 095413.

[20] K.S. Khashan, M.S. Jabir, and F.A. Abdulameer, Carbon nanoparticles decorated with cupric oxide Nanoparticles prepared by laser ablation in liquid as an antibacterial therapeutic agent. Materials Research Express, 2018, 5(3): 035003.

[21] W.K. Kadhim, U.M. Nayef, and M.S. Jabir, Polyethylene glycol-functionalized magnetic $\left(\mathrm{Fe}_{3} \mathrm{O}_{4}\right)$ nanoparticles: a good method for a successful antibacterial therapeutic agent via damage DNA molecule. Surface Review and Letters, 2019: 1950079.

[22] M.S. Jabir, U.M. Nayef, W.K. Abdulkadhim, et al., Supermagnetic $\mathrm{Fe}_{3} \mathrm{O}_{4}$-PEG nanoparticles combined with NIR laser and alternating magnetic field as potent anti-cancer agent against human ovarian cancer cells. Materials Research Express, 2019, 6: 115412.

[23] M.S. Jabir, U.M. Nayef, and W.K.A. Kadhim, Polyethylene glycol-functionalized magnetic $\left(\mathrm{Fe}_{3} \mathrm{O}_{4}\right)$ nanoparticles: a novel DNA-mediated antibacterial agent. Nano Biomedicine \& Engineering, 2019, 11(1): 18-27.

[24] E. Palaska, G. Şahin, P. Kelicen, et al., Synthesis and anti-inflammatory of 1-acylthiosemicarbazide, 1,3,4-oxadiazoles, 1,3,4-thiadiazoles and 1,2,4-triazole-3thiones. Il Farmaco, 2002, 57(2): 101-107.

[25] J. Singh, P. Singh, Synthesis, spectroscopic characterization, and in vitro antimicrobial studies of pyridine-2-carboxylic acid N'-(4-chloro- 
benzoyl)-hydrazide and its Co (II), Ni (II), and $\mathrm{Cu}$ (II) complexes. Bioinorganic Chemistry and Applications, 2012.

[26] G.B. Bagihalli, P.G. Avaji, S.A. Patil, et al., Synthesis, spectral characterization, in vitro antibacterial, antifungal and cytotoxic activities of $\mathrm{Co}$ (II), $\mathrm{Ni}$ (II) and $\mathrm{Cu}$ (II) complexes with 1,2,4-triazole Schiff bases. European Journal of Medicinal Chemistry, 2008, 43(12): 26392649.

[27] T.R. Rao, A. Prasad, Synthesis and spectral studies on $3 \mathrm{D}$ metal complexes of mesogenic Schiff base ligands. Part 1. Complexes of N - (4 - butylphenyl) salicylaldimine. Synthesis and Reactivity in Inorganic, Metal-Organic and Nano-Metal Chemistry, 2005, 35(4): 299-304.

[28] R.E. de Paiva, C. Abbehausen, A.F. Gomes, et al., Synthesis, spectroscopic characterization, DFT studies and antibacterial assays of a novel silver (I) complex with the anti-inflammatory nimesulide. Polyhedron, 2012, 36(1): 112-119.

[29] Y.N. Zhang, H. Wang, J.Q. Liu, et al., Novel silver (I) compounds assembled from hybrid ligands based on linear or T-shaped coordination environment. Inorganic Chemistry Communications, 2009, 12(7): 611-614.

[30] M. Haga, E.S. Dodsworth, A.B.P. Lever, et al., Synthesis, characterization, and charge distribution of bis (4-tert-butylpyridine) bis (3, 5-di-tert-butylquinone) ruthenium. Journal of the American Chemical Society, 1986, 108(23): 7413-7414.

[31] R.A. Saleh, H.A. Mohammad, T.I. Gerber, et al., Synthesis and characterization of mono and mixed ligand, $\mathrm{Ni}$ (II), Pd (II) and Pt (II) complexes of S-5-phenyl-1, 3, 4-oxadiazole-2-yl benzothioate with some tertiary diphosphines ligands. AIP Conference Proceedings, 2017,
1888(1): 020047.

[32] M. Koparır, A. Çetin, and A. Cansız, 5-Furan-2yl [1,3,4] oxadiazole-2-thiol, 5-furan-2yl-4H [1,2,4] triazole-3thiol and their thiol-thione tautomerism. Molecules, 2005, 10(2): 475-480.

[33] S. Amer, N. El-Wakiel, and H. El-Ghamry, Synthesis, spectral, antitumor and antimicrobial studies on $\mathrm{Cu}$ (II) complexes of purine and triazole Schiff base derivatives. Journal of Molecular Structure, 2013, 1049: 326-335.

[34] A.K. Singh, O.P. Pandey, and S.K. Sengupta, Synthesis, spectral characterization and biological activity of zinc (II) complexes with 3-substituted phenyl-4-amino-5hydrazino-1,2,4-triazole Schiff bases. SpectrochimicaActa Part A: Molecular and Biomolecular Spectroscopy, 2012, 85(1): 1-6.

[35] S.F. Barbuceanu, G. Saramet, G.L. Almajan, et al., New heterocyclic compounds from 1,2,4-triazole and 1,3,4-thiadiazole class bearing diphenylsulfone moieties. Synthesis, characterization and antimicrobial activity evaluation. European Journal of Medicinal Chemistry, 2012, 49: 417-423.

[36] R.M. Silverstein, G.C. Bassler, and D.J. Kiemle, Spectrometric identification of organic compounds, 7 th ed. John Wiley and Sons, 2005.

Copyright $\subset$ Atheer Ali, Rehab Al-Hassani, Dhia Hussain, Majid Jabir, and Hamid Meteab. This is an open-access article distributed under the terms of the Creative Commons Attribution License, which permits unrestricted use, distribution, and reproduction in any medium, provided the original author and source are credited. 